\title{
Seasonal Variation
}

\section{Mortality From Pulmonary Fibrosis Is Greatest in the Winter}

\author{
Amy L. Olson, MD, MSPH; Jeffrey J. Swigris, DO, MS; \\ Ganesh Raghu, MD, FCCP; and Kevin K. Brown, MD, FCCP
}

\begin{abstract}
Background: In the general population, rates of certain respiratory infections (and mortality from these infections) are higher in winter. We hypothesized that in patients with idiopathic pulmonary fibrosis (IPF) and/or pulmonary fibrosis (PF) from any cause, death rates would be increased during the winter season, independent of recognized infection. Our objective was to determine if mortality rates from IPF and/or PF of any cause exhibit seasonal variation.

Methods: Using death records from the National Center for Health Statistics, we calculated monthly mortality rates for persons with $\mathrm{PF}$ and developed a multivariable model to determine if these mortality rates exhibited seasonal variation.

Results: From spring of 1992 to fall of 2003, there were 27,367,580 deaths in the United States and 170,984 decedents with PF. The average mortality rate among all persons with $P F$ was $17.1 \%$ higher in winter $(p<0.0001), 12.7 \%$ higher in spring $(p<0.0001)$, and $5.2 \%$ higher in fall $(p=0.0002)$ than in summer months. These findings persisted when records with a diagnostic code for pneumonia were excluded from the analysis as well as when only records in which PF was the underlying cause of death were included in the analysis.

Conclusions: Mortality rates from PF exhibit significant seasonal variation, with the highest rates occurring in the winter, even when recognized infection is excluded. Further studies are necessary to determine if this seasonal variation exists in a prospective cohort and, if so, to uncover its etiology.

(CHEST 2009; 136:16-22)
\end{abstract}

Abbreviations: ICD-9 = International Classification of Diseases, Ninth Revision; ICD-10 = International Classification of Diseases, Tenth Revision; IPF = idiopathic pulmonary fibrosis; NCHS = National Center for Health Statistics; $\mathrm{PF}=$ pulmonary fibrosis; $\mathrm{PIPF}=$ postinflammatory pulmonary fibrosis; $\mathrm{UCD}=$ underlying cause of death

$\mathbf{P}$ rogressive fibrosing interstitial lung disease, or pulmonary fibrosis $(\mathrm{PF})$, comprises a group of chronic respiratory conditions defined radiographically by the presence of diffuse parenchymal abnormalities and pathologically by the presence of abnormal collagen deposition. The most common member of this group is idiopathic pulmonary fibrosis (IPF), a distinct clinical disorder of chronic fibrosing interstitial pneumonia of unknown etiology with a histologic pattern of

From the Division of Pulmonary Sciences and Critical Care Medicine (Dr. Olson), University of Colorado Health Sciences Center, Denver, CO; Interstitial Lung Disease Division (Drs. Swigris and Brown), National Jewish Medical and Research Center, Denver, CO; and Division of Pulmonary and Critical Care Medicine (Dr. Raghu), University of Washington Medical Center, Seattle, WA.

This work was performed at National Jewish Medical and Research Center, Denver, CO.

The authors have no conflicts of interest to disclose. usual interstitial pneumonia. ${ }^{1}$ IPF carries a fatal prognosis with a median survival of 2.5 to 3.5 years, and it has no effective medical therapy. ${ }^{2}$ Studies have reported an increase in the incidence of IPF, ${ }^{3-5}$ as well as a rising mortality from $\mathrm{PF},{ }^{6}$ suggesting a disease burden greater than previously believed.

New evidence also suggests that a higher proportion of patients with $\mathrm{PF}$ are dying from their lung disease rather than from commonly occurring co-

Manuscript received March 12, 2008; revision accepted July 16, 2008.

Reproduction of this article is prohibited without written permission from the American College of Chest Physicians (www.chestjournal. org/site/misc/reprints.xhtml).

Correspondence to: Amy L. Olson, MD, University of Colorado Health Sciences Center, Division of Pulmonary Sciences and Critical Care Medicine, 4200 East Ninth Ave, C272, Denver, CO 80262; e-mail: amy.olson@uchsc.edu

DOI: 10.1378/chest.08-0703 
morbid conditions. ${ }^{6-9}$ In a summary of six case series published between 1964 and 1983, Panos and colleagues $^{7}$ reported that $38.7 \%$ of decedents with $\mathrm{PF}$ died from respiratory failure; many cases were undoubtedly due to disease progression. Similarly, Mannino and colleagues, ${ }^{8}$ using mortality data from 1979 to 1991, found that 50\% of patients with PF died from PF. Using population data from 1992 to 2003, we reported that among patients with PF, $60 \%$ of deaths are attributed to the disease itself. 8,9 Martinez and colleagues ${ }^{10}$ found that $89 \%$ of the deaths occurring in the placebo arm of a recently completed randomized, controlled trial of $\gamma$-interferon for IPF were considered to be due to IPF progression.

The specific mechanisms responsible for disease progression and death due to $\mathrm{PF}$ are unknown, although many patients will die as the result of acute respiratory failure that cannot be explained by a microbiologically defined infection. These so-called acute exacerbations are most clearly defined in IPF 11 but also complicate other forms of $\mathrm{PF} .{ }^{12} \mathrm{We}$ and many others ${ }^{11-12}$ have speculated that death due to disease progression (particularly instances of acute exacerbation) in patients with $\mathrm{PF}$ might be due to undetected infections.

In the general population, rates of particular respiratory infections, and deaths due to such infections, are higher in winter. ${ }^{13-15}$ We hypothesized that respiratory infection is driving mortality in a large proportion of patients with $\mathrm{PF}$, and we sought to determine whether, similar to identifiable respiratory infections, a seasonal variation existed in death rates from $\mathrm{PF}$. In this study, we used the National Center for Health Statistics (NCHS) multiple cause of death database to calculate mortality rates from $\mathrm{PF}$ and to determine if significant seasonal variation exists in mortality rates from $\mathrm{PF}$. Some of the results of this article have previously been presented in abstract form. ${ }^{16}$

\section{Materials AND Methods}

\section{Database}

The NCHS compiles data from all death certificates in the United States and releases the figures in yearly public-use files. ${ }^{17}$ We analyzed these files from 1992 to 2003 . Each annual files contains over two million decedent records, and each record contains demographics (including the month of death), multiple cause of death codes (which identify up to 20 conditions related to death within a section of the record the NCHS calls the record axis), and the singular underlying cause of death (UCD), defined by the World Health Organization as "the disease or injury which initiated the train of events leading to death."18 In this database, from 1992 to 1998, coders at the NCHS coded conditions related to death with the International Classification of Diseases, Ninth
Revision (ICD-9). ${ }^{19}$ After 1998, the NCHS coded conditions related to death with the International Classification of Diseases, Tenth Revision (ICD-10). ${ }^{18}$ Additional specifics of this database related to coding, data maintenance, data quality, and accessibility have previously been described. 8 All data contained in these database files have been de-identified and are of public record; therefore, institutional review board approval for this study was not required.

\section{Case Definition}

In this study, we included all files from decedents with a code for "pulmonary fibrosis" in the record axis; for certain analyses, we included only those files in which "pulmonary fibrosis" was coded as the ultimate UCD. From 1992 to 1998, we captured decedents with PF with either (or both) ICD-9 codes 516.3 (IPF) or 515 (postinflammatory pulmonary fibrosis [PIPF]). Because of the change in coding from ICD-9 to ICD-10, we captured decedents with PF after 1998 with ICD-10 code J84.1 (a code that comprises both IPF and PIPF).

\section{Statistical Analysis}

We performed three analyses on files that contained diagnostic codes for PF. In the first analysis, we included all records in which codes for PF occurred anywhere in the axis code. In the second analysis, we included only those files in which PF was coded as the UCD. Recognizing that, in the general population, there is seasonal variation in the incidence of, and mortality rates from, infectious pneumonia. ${ }^{13,14,20-22}$ In the third analysis, we excluded any records in which a code for "pneumonia" appeared in the record axis. Specifics of the ICD codes for conditions or diseases that led to the exclusion of any file are outlined in the Appendix.

For each of the three analyses, we calculated monthly mortality rates and then established average seasonal rates. Seasons of death were defined in the following manner: "winter" from December through February; "spring" from March through May; "summer" from June through August; and "fall" from September through November. ${ }^{13}$ To calculate monthly mortality rates, the denominators used were population estimates from the US Census Bureau: July 1 intercensal population estimates (from 1992 to 1999 ) and July 1 population projections (from 2000 to 2003). ${ }^{23}$ This midyear population estimate was used as the denominator for any month of that year. When compared with linear interpolation of the population estimates or projections to approximate the population at the beginning of each month, this method (of using the midyear population as the denominator) minimizes potential overestimation of mortality rates in the beginning of each year, or during most of the winter season.

Poisson multivariable regression analysis was used to evaluate differences in mortality rates between seasons and years of death in those with PF. To account for a possible interaction between seasons and years of death, that is, to consider the possibility that seasonal death epidemics occurred in any 1 year, second-order interactions between the season of death and year of death were evaluated. ${ }^{24}$ No significant second-order interactions were identified, so this variable was excluded from the final models. To confirm this approach, as seasonal differences in mortality rates among patients with COPD are recognized, ${ }^{25,26}$ similar methods were used to analyze seasonal differences in mortality rates in COPD as well as lung cancer.

Mortality rates were calculated using software (Microsoft Office Excel 2003 SP2; Microsoft Corporation; Redmond, WA). All data were analyzed using statistical software (SAS version 9.1; SAS Institute; Cary, NC); the GENMOD procedure (SAS Institute) was used to perform the Poisson regression analysis. 


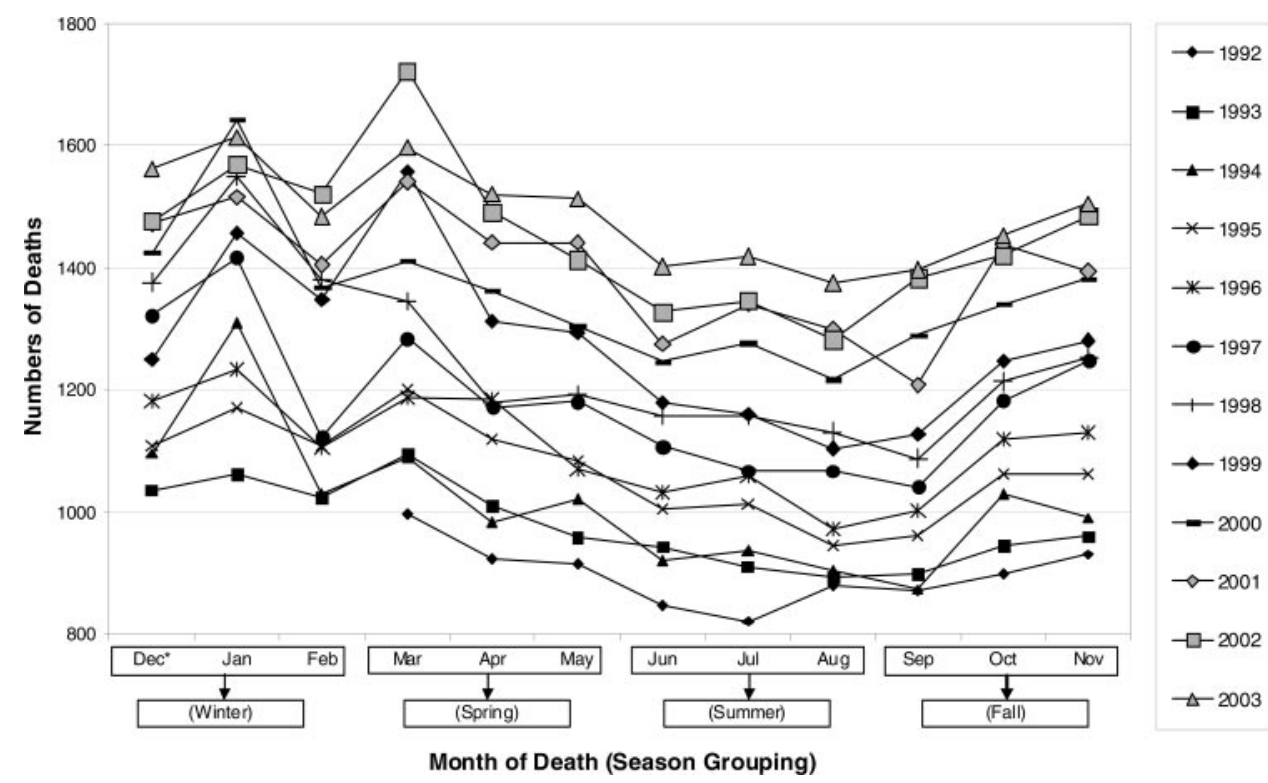

FIGURE 1. Actual number of deaths from PF by month from spring of 1992 to fall of 2003. $*$ Dec $=$ December of the previous year.

\section{RESUlts}

From the spring (March) of 1992 through the fall (November) of 2003, there were 27,367,580 deaths in the United States. Of these deaths, a total of 170,984 records contained a diagnostic code for $\mathrm{PF}$ (ICD-9 codes 515 or 516.3 from 1992 to 1998 or ICD-10 code J84.1 from 1999 to 2003), and 99,142 records documented PF as the UCD. The actual numbers of deaths from $\mathrm{PF}$ by month (from spring of 1992 to fall of 2003) are shown in Figure 1.

Compared with summer, the average monthly mortality rate among patients with $\mathrm{PF}$ was $17.1 \%$ higher in the winter $(\mathrm{p}<0.0001), 12.7 \%$ higher in the spring $(p<0.0001)$, and $5.2 \%$ higher in the fall $(p=0.0002)$
[Fig 2]. Using only those records in which the UCD was $\mathrm{PF}$, we observed the same seasonal variation: mortality rates in patients dying from $\mathrm{PF}$ were $15.9 \%$ higher in the winter $(\mathrm{p}<0.0001), 12.7 \%$ higher in the spring $(p<0.0001)$, and $5.1 \%$ higher in the fall $(\mathrm{p}=0.0008)$ than in the summer (Fig 2).

Examining all files (decedents with or without $\mathrm{PF}$ ) in which a code for pneumonia appeared anywhere in the record axis, the mortality rate was $59.3 \%$ higher in the winter $(p<0.0001), 29.4 \%$ higher in the spring $(\mathrm{p}<0.0001)$, and $10.3 \%$ higher in the fall $(\mathrm{p}=0.0026)$ than in the summer (Fig 3). Considering records from all patients with $\mathrm{PF}$ but excluding those records with a diagnostic code for pneumonia,

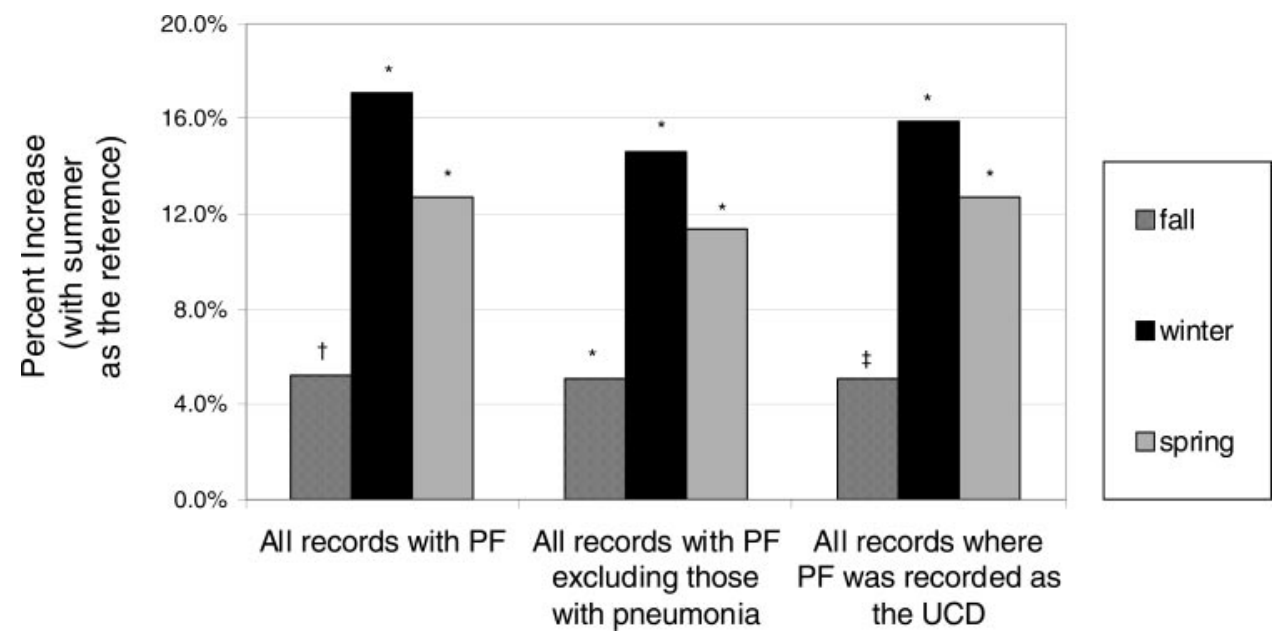

FIGURE 2. Percentage increase in the average monthly mortality from PF by season when compared to summer. ${ }^{*} \mathrm{p}<0.0001,+\mathrm{p}=0.0002, \stackrel{+}{+} \mathrm{p}=0.0008$. 


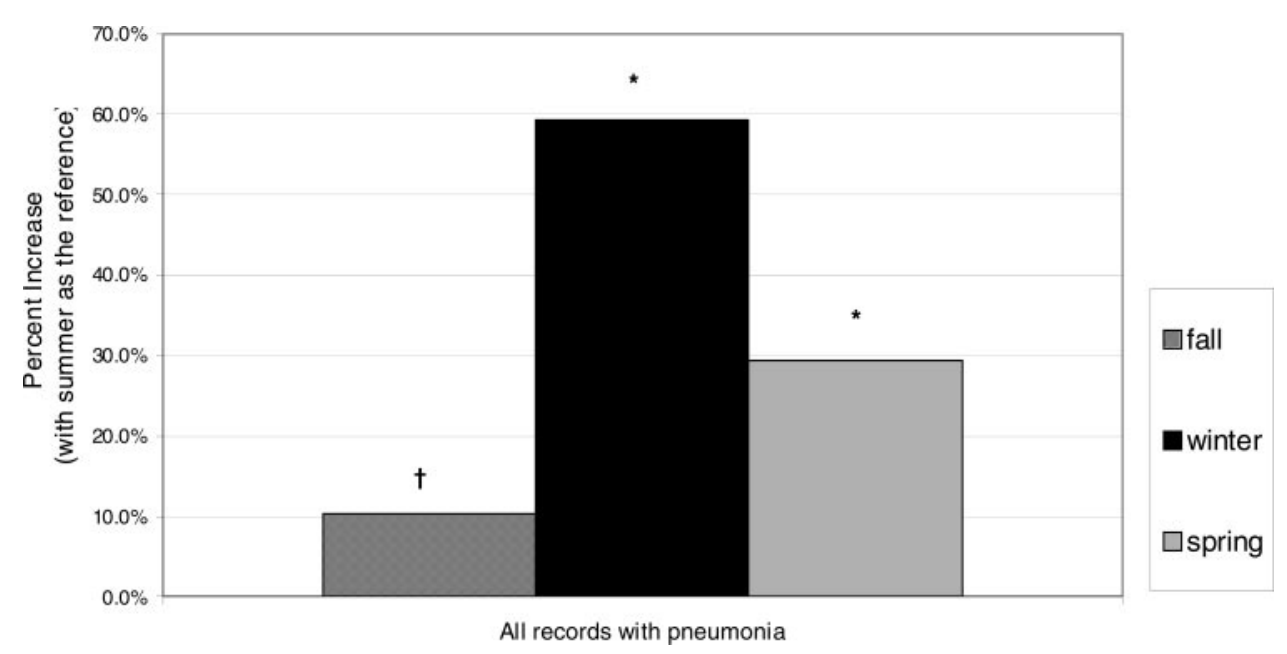

FIGURE 3. Percentage increase in the average monthly mortality from pneumonia by season when compared to summer. $* \mathrm{p}<0.0001, \mathrm{tp}=0.0026$.

the seasonal variation persisted: the mortality rate was $14.6 \%$ higher in the winter $(p<0.0001), 11.4 \%$ higher in the spring $(\mathrm{p}<0.0001)$, and $5.1 \%$ higher in the fall than in the summer $(\mathrm{p}<0.0001)$ [Fig 2].

Consistent with prior data, ${ }^{25-26}$ we identified significant seasonal variation in mortality rates from COPD. Including all records with a diagnostic code for COPD, the mortality rate was $29.0 \%$ higher in the winter $(p<0.0001)$ and $17.8 \%$ higher in spring $(p<0.0001)$ than the summer; no significant difference was found between rates in the fall and summer $(p=0.1223)$. Considering records from all patients with COPD but excluding those records with a diagnostic code for pneumonia, the seasonal variation persisted: the mortality rate was $23.7 \%$ higher in the winter $(\mathrm{p}<0.0001)$ and $15.2 \%$ higher in the spring $(\mathrm{p}<0.0001)$ than the summer. No significant difference was found between rates in the fall and summer $(p=0.1891)$ [Fig 4].

Notably less seasonal variation was found in the mortality rates from lung cancer. The mortality rate in decedents with lung cancer was $2.9 \%$ higher in the winter $(p=0.0004)$ than the summer. No significant variation was found in rates between summer and fall $(\mathrm{p}=0.0946)$ or between summer and spring $(p=0.0970)$ [Fig 4]. Considering records from all patients with lung cancer and then excluding any record with a diagnostic code for pneumonia that appeared anywhere in the record axis, a small increase in the mortality rate in the winter persisted $(2.7 \%, \mathrm{p}=0.0012)$ when compared to the summer (Fig 4).

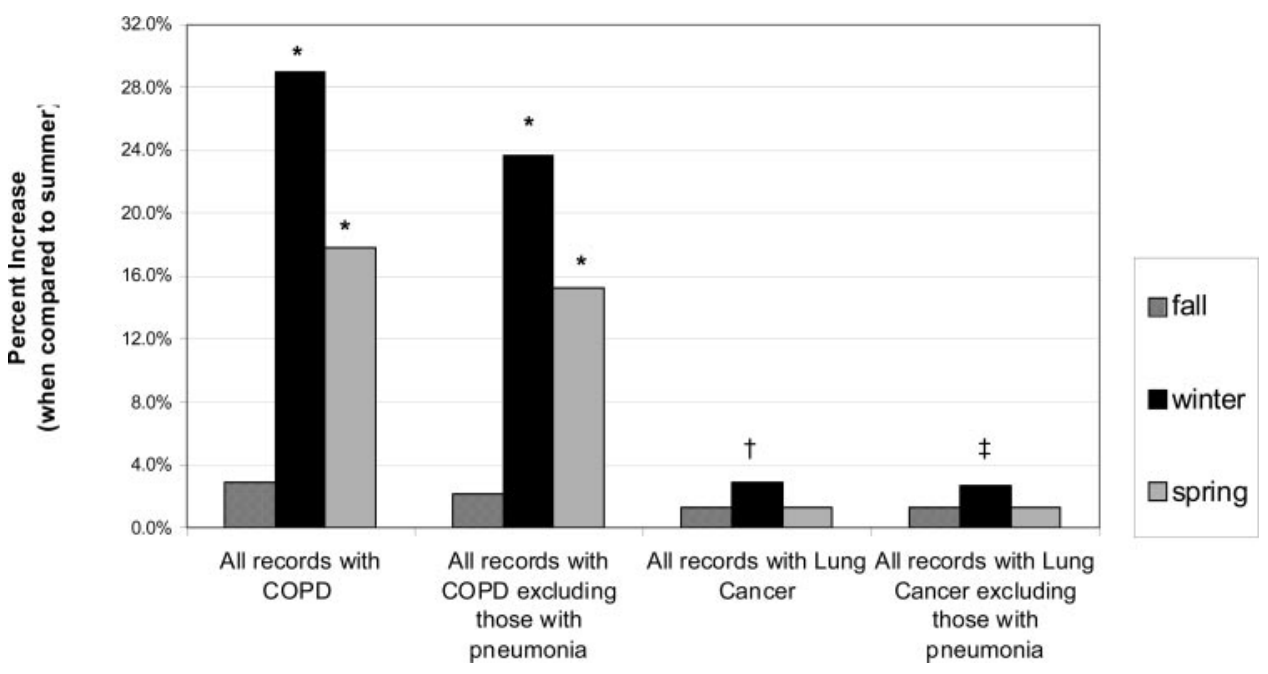

FIGURE 4. Percentage increase in the average monthly mortality from COPD and lung cancer by season when compared to summer. ${ }^{*} \mathrm{p}<0.0001,{ }^{\dagger} \mathrm{p}=0.0004, \stackrel{+}{+} \mathrm{p}=0.0012$. 


\section{DisCUSSION}

We believe this to be the first published study to look for and find seasonal variation in mortality rates in patients with PF. Using records from March of 1992 through October 2003, we analyzed nearly $28,000,000$ death files, identified $>170,000$ decedents with $\mathrm{PF}$, and found significant seasonal variation in mortality rates of patients dying with $\mathrm{PF}$. The highest mortality rates from $\mathrm{PF}$ were observed in the winter months, and this seasonal difference persisted when we analyzed only records in which PF was listed as the UCD.

Seasonal variation in mortality with an increased winter incidence of (and mortality rates from) pneumonia is well-established and reconfirmed in this data set. ${ }^{13-15,20}$ The seasonal variation is likely due in part to infection with influenza (which occurs more commonly from December through March), respiratory syncytial virus (which occurs more commonly in the spring), and possibly superimposed bacterial infections. ${ }^{20-22,25}$ However, clinically recognized infectious pneumonia does not appear to account for the excess winter and spring rates in patients with $\mathrm{PF}$; for when we excluded records of patients with $\mathrm{PF}$ in which pneumonia appeared anywhere in the file, mortality rates among patients with $\mathrm{PF}$ remained substantially higher in the winter and spring.

For comparison, we performed similar analyses for COPD and lung cancer. It is widely recognized that the most frequent precipitants of acute COPD exacerbations are viral and bacterial infections (in the absence of obvious pneumonia), ${ }^{25}$ that COPD exacerbations are $50 \%$ more likely to occur in the winter, ${ }^{26}$ and that mortality from COPD is higher in the winter months. ${ }^{13,27,28}$ Theories for the increased frequency of disease exacerbations and death in patients with COPD during the winter months are almost all focused on a likely infectious trigger and include improved survival of respiratory viruses in colder weather, crowding of people indoors during the winter, and possibly a seasonal-related reduced immunologic response. ${ }^{27}$ Similar to previous studies, we found the highest mortality rate from COPD in the winter, even after records containing a diagnostic code for pneumonia were excluded.

Unlike COPD, lung cancer (and resultant mortality from lung cancer) is not marked by acute infectious exacerbations of the underlying disease and would not be expected to exhibit as much seasonal variation. This expectation was confirmed by our data. In contrast to COPD, although the mortality rates from lung cancer showed a significant increase in the winter when compared with summer, the increase was trivial $(2.7 \%)$, a small difference that was also noted in a study from Nakaji and col- leagues. ${ }^{13}$ These investigators examined all-cancer mortality data in Japan from 1970 to 1999, and, after adjusting for long-time trends and temperature, they found that the relative mortality rate increased only $4.0 \%$ during the year (from a low in April to a high in October). Due to the small increase, they could not draw any reliable conclusions.

The increase in mortality during the winter among decedents with PF parallels that seen in COPD and, similar to COPD, we hypothesize that the excess mortality in winter has an infectious trigger. Host factors may play a role in the increased likelihood for infection to develop during the winter months. For example, researchers ${ }^{28}$ in the European Union showed that cold stress correlates with an increase in allcause and respiratory-specific mortality during the winter. Alternatively, photoperiods (the amount of light exposure during a day) may contribute; in animal models, short-day photoperiods result in decreased phagocytosis and less granulocyte oxidative burst activity. ${ }^{29}$ Investigators speculate that melatonin is involved in this immune down-regulation. After treatment with melatonin, mice exposed to a constant photoperiod exhibited increased lymphocyte response to mitogen stimulation. ${ }^{30}$

As we previously reported and as evident in the results from this study in Figure 1, mortality rates from $\mathrm{PF}$ have increased over time. ${ }^{6}$ However, an increase over time in the excess mortality in the winter months when compared to the summer months did not account for the overall increase in mortality from 1992 to 2003 because mortality rates during any given season generally increased over time, and the increase in the excess winter mortality was independent of the year in the model. In addition, when we assessed for a possible seasonal epidemic during any given year, no increase in mortality by season for any given year was identified.

This study has a number of limitations. We had to rely on death certifiers to identify cases and code conditions correctly on the death certificate. We are unable to determine the accuracy of this process. However, a previous study ${ }^{31}$ on the accuracy of coded death certificate data found that PF (defined by combining ICD-9 codes 515 [PIPF] and 516.3 [IPF]) was never recorded in a state mortality database unless the patient had a diagnosis of $\mathrm{PF}$ prior to death. Conversely, among patients with a clinical diagnosis of $\mathrm{PF}$ prior to death, only $5 \%$ carried a code for PF into the state mortality database. ${ }^{31}$ If these findings hold true for national data, we believe the coded diagnosis of $\mathrm{PF}$ is accurate but the mortality rates from PF used in our models significantly underestimate the true mortality rates from $\mathrm{PF}$. We have previously shown that excluding secondary codes for underlying conditions (eg, connec- 
tive tissue disease, hypersensitivity pneumonitis, sarcoidosis) that may cause $\mathrm{PF}$ does not result in considerable differences in mortality rates; thus, we can make either of two assumptions: (1) the cause of $\mathrm{PF}$ is unknown in the majority of decedents (in which case it is reasonable to extrapolate the results of this study to patients with IPF); or (2) coding patterns are inadequately sensitive to determine the underlying etiology of PF from a death certificate (and the findings from the current study apply to all cases of PF regardless of the underlying etiology). ${ }^{8}$

The incidence ${ }^{3-5}$ as well as the mortality associated with $\mathrm{PF}^{6}$ are rising and are associated with an increasing risk of death from progressive lung disease rather than from commonly occurring comorbid conditions. ${ }^{6-9}$ Analysis of a recently completed controlled treatment trial ${ }^{10}$ found that $89 \%$ of the deaths occurring in the placebo arm were considered to be due to IPF progression; of these deaths, half were categorized as acute with decompensation occurring over 4 weeks or less, with the other half considered subacute with worsening occurring over weeks to months. These accelerated declines ${ }^{32,33}$ and acute exacerbations of IPF (and other fibrotic lung diseases) ${ }^{34}$ have recently gained attention due to their high direct mortality rate, their unpredictable nature (as they do not appear to be related to the level of pulmonary function derangement), ${ }^{10,11,35}$ and the lack of effective therapy. ${ }^{11}$ Under these conditions, the absence of an underlying mechanism is even more frustrating. From the data in this study, we cannot determine the etiology of the increased mortality from $\mathrm{PF}$ in the winter. However, the similar seasonal variation in deaths from PF, COPD, pneumonia, and recognized viral illness support an infectious etiology. $13-15,21,22,25,26$

The absence of a code for infection when infection is actually present may result from either of two causes: (1) the failure to clinically consider or to systematically evaluate for it; or (2) the presence of an infectious agent that is difficult to identify or previously unknown. However, the absence of a clearly recognized infection in PF deaths is supported by autopsy studies ${ }^{33,36}$ in which it is rare to find a specific infection and the underlying pathology of the lung is often underlying fibrosis with superimposed diffuse alveolar damage, a pattern not unique to pneumonia. In $\mathrm{PF}$, it could be that an infectious agent activates or accelerates the fibrotic process without causing classic infection. McMillan and colleagues ${ }^{37}$ described a murine model of fluorescein isothiocyanate-induced $\mathrm{PF}$ in which infection with a $\gamma$-herpesvirus results in an exacerbation of the fibrotic lung disease manifest by an increase in the total lung collagen and histopathologic findings of acute lung injury. Alternatively, it is certainly possible that the increased mortality in the winter in patients with $\mathrm{PF}$ is entirely unrelated to infection and is due to other unidentified seasonalrelated changes (such as in behavioral patterns or environmental alterations), ${ }^{27,28}$ or to noninfectious aberrations in immune or mesenchymal cell function induced by other unknown factors. ${ }^{20,29,30}$

Similar to other pulmonary conditions in which seasonal variation has been reported and has led to alternative hypotheses, ${ }^{38}$ identification of novel risk factors, ${ }^{39}$ insight into the mechanisms involved in the pathogenesis of disease, ${ }^{40,41}$ and recommendations for changes in health policy, ${ }^{42}$ we believe our findings are relevant to better understanding this complex disease. While our study only provides a signal, the identification of seasonal variation in mortality rates from $\mathrm{PF}$ has important implications, including improved knowledge of disease epidemiology, an explanation for variability in case-fatality rates between studies ${ }^{13}$ and, we believe, insight into the pathogenesis of the ultimate cause of death in these patients. ${ }^{6-10,14,15}$

In conclusion, mortality rates from $\mathrm{PF}$ exhibit significant seasonal variation, with the highest rates occurring in the winter. Seasonal variation in PF mirrors COPD exacerbations and mortality, raising suspicion that an unidentified infectious trigger may play a significant role. Our findings provide further insight into the natural history of $\mathrm{PF}$ and raise several important questions about the etiology. Further research is necessary to determine if seasonal variation exists in a prospectively collected cohort of patients with $\mathrm{PF}$ and, if confirmed, to determine its etiology.

\section{APPENDIX}

From 1992 to 1998, ICD-9 definitions of disease entities are as follows: infectious pneumonia, ICD-9 codes 480 through 487.8; COPD, ICD-9 codes 490 through 492 and 496; and lung cancer, ICD-9 codes 162 through 162.9-excluding 162.0 (malignant neoplasms of the trachea). After 1998, ICD-10 definitions of disease entities included: infectious pneumonia, ICD-10 codes J09 through J18.9; COPD, ICD-10 codes J40 through J44.9; and lung cancer, ICD-10 codes C34 through C34.9.

\section{REFERENCES}

1 American Thoracic Society/European Respiratory Society. Idiopathic pulmonary fibrosis: diagnosis and treatment; international consensus statement. Am J Respir Crit Care Med 2000; 161:646-664

2 American Thoracic Society/European Respiratory Society. International multidisciplinary consensus classification of the idiopathic interstitial pneumonias. Am J Respir Crit Care Med 2002; 165:277-304

3 Coultas DB, Hubbard R. Epidemiology of idiopathic pulmonary fibrosis. In: Lynch JP, ed. Idiopathic pulmonary fibrosis. New York, NY: Marcel Dekker, 2004; 1-30

4 Raghu G, Weycker D, Edelsberg J, et al. Incidence and 
prevalence of idiopathic pulmonary fibrosis. Am J Respir Crit Care Med 2006; 174:810-816

5 Gribbin J, Hubbard RB, Le Jeune I, et al. The incidence and mortality of idiopathic pulmonary fibrosis and sarcoidosis in the UK. Thorax 2006; 61:980-985

6 Olson AL, Swigris JJ, Lezotte D, et al. Mortality from pulmonary fibrosis increased in the United States from 1992 to 2003. Am J Respir Crit Care Med 2007; 176:277-284

7 Panos RJ, Mortenson RL, Niccoli SA, et al. Clinical deterioration in patients with idiopathic pulmonary fibrosis: causes and assessment. Am J Med 1990; 88:396-404

8 Mannino DM, Etzel RA, Parrish RG. Pulmonary fibrosis deaths in the United States, 1979-1991: an analysis of multiple-cause mortality data. Am J Respir Crit Care Med $1996 ; 153: 1548-1552$

9 Olson AL, Swigris JJ, Lezotte D, et al. The underlying cause-of-death in decedents with pulmonary fibrosis, 19922003 [abstract]. Am J Respir Crit Care Med 2007; 175(suppl): A569

10 Martinez FJ, Sarfrin S, Weycker D, et al. The clinical course of patients with idiopathic pulmonary fibrosis. Ann Intern Med 2005; 142:963-967

11 Collard HR, Moore BB, Flaherty KR, et al. Pulmonary perspective: acute exacerbations of idiopathic pulmonary fibrosis. Am J Respir Crit Care Med 2007; 176:636-643

12 Churg A, Müller NL, Silva CI, et al. Acute exacerbation (acute lung injury of unknown cause) in UIP and other forms of fibrotic interstitial pneumonias. Am J Surg Pathol 2007; 31:277-284

13 Nakaji S, Parodi S, Fontana V, et al. Seasonal changes in mortality rates from main causes of death in Japan (19701999). Eur J Epidemiol 2004; 19:905-913

14 Danai PA, Sinha S, Moss M, et al. Seasonal variation in the epidemiology of sepsis. Crit Car Med 2007; 35:410-415

15 Reichert TA, Simonsen L, Sharma A, et al. Influenza and the winter increase in mortality in the United States, 1959-1999. Am J Epidemiol 2004; 160:492-502

16 Olson AL, Swigris JJ, Raghu G, et al. Seasonal variation: mortality from pulmonary fibrosis is greatest in the winter [abstract]. Am J Respir Crit Care Med 2008 (in press)

17 Centers for Disease Control and Prevention, National Center for Health Statistics. Public use data tape documentation: multiple cause of death for ICD-9 1992 data. Hyattsville, MD: US Department of Health and Human Services, 1994

18 ICD-10: international statistical classification of diseases and related health problems; tenth revision. Geneva, Switzerland: World Health Organization, 2003

19 International classification of diseases, ninth revision. Washington, DC: US Public Health Service, US Government Printing Office, 1980; publication (PHS) 80-1260

20 Dowell SF. Seasonal variation in host susceptibility and cycles of certain infectious disease. Emerg Infect Dis 2001; 7:369374

21 Talbot TR, Poehling KA, Hartert TV, et al. Seasonality of invasive pneumococcal disease: temporal relation to documented influenza and respiratory syncytial viral circulation. Am J Med 2005; 118:285-291

22 Hament JM, Kimpen JL, Fleer A, et al. Respiratory viral infection predisposing for bacterial disease: a concise review. FEMS Immunol Med Microbiol 1999; 26:189-195

23 United States Census Bureau. Intercensal population esti- mates. Available at: http://www.census.gov. Accessed November 17, 2006

24 Rosner B. Inference for stratified person-time data. In: Crockett C, ed. Fundamentals of biostatistics. 6th ed. Belmont, CA: Thomson, 2006; 763-771

25 Burge PS. Prevention of exacerbations: how are we doing and can we do better? Proc Am Thorac Soc 2006; 3:257-261

26 Donaldson GC, Wedzicha JA. COPD exacerbations: 1. Epidemiology. Thorax 2006; 61:164-168

27 Wilkinson P, Pattenden S, Armstrong B, et al. Vulnerability to winter mortality in elderly people in Britain: population based study. BMJ 2004; 329:647-652

28 The Eurowinter Group. Cold exposure and winter mortality from ischaemic heart disease, cerebrovascular disease, respiratory disease, and all causes in warm and cold regions of Europe. Lancet 1997; 349:1341-1346

29 Yellon S, Fagoaga O, Nehlsen-Cannarella S. Influence of photoperiod on immune cell functions in the male Siberian hamster. Am J Physiol 1999; 276:R97-R102

30 Demas G, Nelson R. Exogenous melatonin enhances cellmediated, but not humoral, immune function in adult male deer mice. J Biol Rhythms 1998; 13:245-252

31 Coultas DB, Hughes MP. Accuracy of mortality data for interstitial lung disease in New Mexico, USA. Thorax 1996; 51:717-720

32 Akira M, Hamada H, Saktani M, et al. CT findings during phase of accelerated deterioration in patients with idiopathic pulmonary fibrosis. AJR Am J Roentgenol 1997; 168:79-83

33 Rice AJ, Wells AU, Bouros D, et al. Terminal diffuse alveolar damage in relation to interstitial pneumonias: an autopsy study. Am J Clin Pathol 2003; 119:709-714

34 Silva CI, Müller NL, Fujimoto K, et al. Acute exacerbation of chronic interstitial pneumonia: high-resolution computed tomography and pathologic findings. J Thorac Imaging 2007; 22:221-229

35 Kim DS, Park JH, Park BK, et al. Acute exacerbations of idiopathic pulmonary fibrosis: frequency and clinical features. Eur Respir J 2006; 27:143-150

36 Daniels CE, Yi ES, Ryu JH. Autopsy findings in 42 consecutive patients with idiopathic pulmonary fibrosis. Eur Respir J 2008; 32:170-174

37 McMillan TR, Moore BB, Weinberg JB, et al. Exacerbation of established pulmonary fibrosis in a murine model by yherpesvirus. Am J Respir Crit Care Med 2008; 177:771-780

38 Hannu T, Jaakkola MS, Kivisaari L, et al. Season of birth and lung fibrosis among workers exposed to asbestos. Chronobiol Int 2007; 24:539-551

39 Manfredini R, Imberti D, Gallerani M, et al. Seasonal variation in the occurrence of venous thromboembolism: data from the MASTER registry. Clin Appl Thromb Haemost 2009; 15:309-315

40 Lowen AC, Mubareka S, Steel J, et al. Influenza virus transmission is dependent on relative humidity and temperature. PLoS Pathog 2007; 3:1470-1476

41 Baillie SR, Prendergast BJ. Photoperiod regulation of behavioral responses to bacteria and viral mimetics: a test of the winter immunoenhancement hypothesis. J Biol Rhythms 2008; 23:81-90

42 Chen CH, Xirasagar S, Lin HC. Seasonality in adult asthma admissions, air pollutant levels, and climate: a population based study. J Asthma 2006; 43:287-292 